\title{
Evaluation of Physicochemical and Microbiological Parameters of Drinking Water Supplied from Distribution Systems of Kathmandu Municipality
}

\author{
Prabin Shakya ${ }^{1}$, Tista P. Joshi ${ }^{2}$, Dev R. Joshi ${ }^{1}$ and Dwij R. Bhatta ${ }^{1}$ \\ ${ }^{1}$ Central Department of Microbiology \\ Tribhuvan University, Kirtipur, Kathmandu \\ ${ }^{2}$ Nepal Academy of Science and Technology \\ Khumaltar, Lalitpur \\ e-mail: prashal1@gmail.com
}

\begin{abstract}
Microbial pathogens in drinking water are primary cause in gastrointestinal and waterborne diarrheal diseases. Public health authorities still have not achieved success in controlling the most common waterborne diseases in Nepal. The objective of this study was to assess the quality of drinking water supplied from distribution system of Kathmandu. A total of 114 water samples were collected from 4 distribution stations. The physicochemical and microbiological analyses of water were conducted. Heterotrophic plate count (HPC), detection of enteric pathogenic bacteria and antibiotics susceptibility test were done. Distinct variations in physicochemical parameters were observed. The mean free residual chlorine was found $0.24 \mathrm{mg} / \mathrm{l}$. Total Coliforms were found in $61.4 \%$ (70/114) of water samples among which $15.7 \%(11 / 70)$ had thermotolerant Coliforms. In distance, coliforms were found higher in far points $(p=0.002)$. All thermotolerant Coliforms were identified as Escherichia coli. Mean HPC of water was found $\log _{10} 3.15$. The mean HPC of water $(\mathrm{p}=0.003)$ was found higher in far point. In collected samples, 10 different enteric bacteria were isolated in which E. coli was found most predominant followed by Pseudomonas spp., Citrobacter spp., Klebsiella spp., Shigella spp., Proteus spp., Enterobacter spp. Non-Typhii Salmonella spp., Providencia spp., Edwardsiella spp. In antibiotics susceptibility test, Gentamicin and Ofloxacin were found most efficient (100\%) and whereas Ampicillin (11.5\%) was least effective. Multiple antibiotics resistance was found among 5.3\% of isolates.
\end{abstract}

Key words: Coliform, heterotrophic plate count, multiple antibiotics resistance, waterborne diseases

\section{Introduction}

The access to safe drinking water plays crucial role in the public health. In many Asian countries, most of the large cities use tap water supplied from distribution system. The provision of clean and safe drinking water is one of the major infrastructure problems for the urban and semi-urban areas. In urban areas people have access to treated piped water, which is received directly in their homes or at community standpipes. The microbiological quality of drinking water is of serious concern to consumers, water suppliers, regulators and public health authorities. The potential of drinking water to transport microbial pathogens to great numbers of people, causing subsequent illness is found in different countries (Payment 1997, WHOSEARO 2010).
The water contamination with fecal bacteria is a common and persistent problem that has a direct impact on the public health, and in economic and social aspects (Stewart et al. 2007). According to World Health Organization (WHO), water-related diseases are estimated to cause 1.8 million deaths each year, mostly in developing countries and have been the major cause of mortality and morbidity (WHO 2004). In Nepal also diseases caused by contaminated water are among the ten most prevalent waterborne diseases (DoHS 2005 , WHO-SEARO 2010). Water the most vital resource for all kinds of life on this planet, can be extremely dangerous when it becomes the vehicle of transmission of diseases (WHO-SEARO 2010). Occurrence of these diseases can be reduced by improved water supply and proper sanitation. However, outbreaks of water-borne diseases still 
often occur, even in developed countries. Thus, monitoring the levels of contamination and the prevention of disease outbreaks is important from both economic and public health perspective (USEPA 2006, WHO-SEARO 2010).

The present study was carried out to assess the pathogenic and opportunistic pathogenic bacteria along with the physicochemical and microbiological quality of drinking water in distribution system of Kathmandu. Besides, this study also assessed the antimicrobial susceptibility test of isolated bacteria from water samples.

\section{Methodology}

Kathmandu valley was taken as the sample site. A stratified random sampling was conducted. Four drinking water distribution systems were taken as strata, namely Balaju (20 samples), Basbari (34 samples), Minbhawan (40 samples) and Tikabhairab (20 samples), along with distance from the distribution stations. Water samples were collected following the guidelines described by American Public Health Association (APHA 1998). Analysis of the physicochemical parameters of water that is Temperature, turbidity, Conductivity, Residual chlorine (Free, Total and combined residual chlorine) were measured with standard procedures (APHA 1998). DPD ( $N, N$-diethyl$p$-phenylenediamine) colorimetric test was applied to measure Residual chlorine (Free, Total and combined residual chlorine). All laboratory analyses were done at Environmental Research Laboratory of Nepal Academy of Science and Technology.

Water samples were collected in two sterile bottles for microbiological analysis containing sodium thiosulphate at the final volume of $0.01 \%(\mathrm{w} / \mathrm{v})$ to neutralize any free or combined residual chlorine and for physicochemical analysis (APHA 1998 \& September et al. 2007). Heterotrophic plate count was done in water samples by spread plating $1 \mathrm{ml}$ of the appropriate serial dilution using sterile pipette into a sterile petri plate having Plate Count Agar (PCA, HiMedia). It was spread plate by using L-shaped sterile glass rod. The plate was then incubated at $37^{\circ} \mathrm{C}$ for $24-$ $48 \mathrm{hrs}$. After the period of incubation colonies were counted and noted down (September et al. 2007, Collee et al. 1996). Total Coliform was enumerated by the membrane filtration (MF) technique (APHA 1998). Membrane filtration was done in M-Endo agar using sterile membrane filter of pore size $0.45 \mu \mathrm{m}$. The sample of water was well mixed and then $100 \mathrm{~mL}$ of water was poured through funnel and filtered under partial vacuum by using electric vacuum pump. Then the membrane was incubated in $\mathrm{M}$-Endo agar at $37^{\circ} \mathrm{C}$ for 24 to 48hrs. After incubation period, total colony forming unit (CFU) were counted. For this, all green metallic sheen-producing colonies were counted (APHA 1998).

For the determination of Salmonella spp., Shigella spp. $5 \mathrm{ml}$ of water were enriched in $45 \mathrm{~mL}$ Selenite F (SF) broth then subcultured on a selective enteric medium, Xylose lysine deoxycholate (XLD) agar. The plate was incubated at $37^{\circ} \mathrm{C}$ for 24 hours. Similarly for Vibrio spp., $1 \mathrm{ml}$ of water was enriched by inoculating into $9 \mathrm{~mL}$ of $1 \%$ alkaline peptone water incubated at $37^{\circ} \mathrm{C}$ for 6 to 8 hours. Then a loop-full of the enrichment broth was streaked on Thiosulfate-citrate-bile saltssucrose (TCBS) agar medium plate incubated at $37^{\circ} \mathrm{C}$ for 24 hours (Collee et al. 1996).

Bacterial colonies producing green metallic sheen on M-Endo agar were sub-cultured in Nutrient Agar (NA) and then transferred to Brillant Green Lactose Broth with inverted/durham's tube and incubated at $44.5^{\circ} \mathrm{C}$ (Collee et al. 1996) for 24-48 hrs. After the period of incubation, acid and gas production were observed in the inoculated tubes. All colonies with different characteristics from M-Endo agar, XLD agar and TCBS agar were streaked onto NA to get pure culture. Bacteria isolated on respective selective or differential media were identified on the basis of their colonial, morphological characteristics and biochemical characteristics. Identification was carried out following Bergey's Manual of Systematic Bacteriology (Holt et al. 1994).

Antibiotic susceptibility test was conducted for a 38 bacterial isolates of water, selected proportionately against 12 different antibiotics using standard disk diffusion method (Bauer et al. 1966). Antibiotics Resistance (AR) and multiple antibiotics resistance (MAR) was determined as those which were at least resistance to one antibiotic and at least two antibiotics or more respectively (Gaur 1992). Antibiotic disk quality was assessed using E. coli ATCC 25922 and Klebsiella pneumoniae ATCC 700603 obtained from National Public Health Laboratory (NPHL), Kathmandu, Nepal. Statistical 
analysis was conducted using Statistical Package for Social Science (SPSS) ver. 16.

\section{Results and Discussion}

A total of 114 water samples were analyzed from four different distribution systems that supply drinking water from Balaju (20), Bansbari (34), Minbhawan (40) and Tikabhairab (20) distribution stations.

In physicochemical parameter, conductivity (14.9\%), turbidity (20.2\%) of sample crossed the permissible guideline value of WHO and also national standard. Variations in temperature of the tested water sample were found which ranged from $12^{\circ} \mathrm{C}-27.3^{\circ} \mathrm{C}$, with the mean temperature of $17.81^{\circ} \mathrm{C}$. However, previous studies didn't found any distinct variation in physicochemical parameters (Shrestha 2008, Aryal 2009). Though temperature does not have direct health impact, but, drinking water having high temperature may impact on its aesthetic quality, lead to the higher rate of chemical reactions in water, reduce solubility of gases and amplify the tastes and odor and also lead to leaching of vinyl chloride form polyvinyl chloride (PVC) pipe (Flournoy et al. 1999). High temperature and $\mathrm{pH}$ enhances the growth of microorganisms both in planktonic (free floating) and sessile (attached) form by changing electrostatic interactions between surfaces and microorganisms, enzymatic reaction and many other properties such as diffusivity, solubility etc. In the study, conducted in USA the coliform bacteria increased significantly in drinking water distribution system when the temperature increased to over $15^{\circ} \mathrm{C}$ (USEPA 2006). Turbidity can be used as an indicator for identifying contamination entry, hydraulic problems in the distribution system. Besides, increased turbidity can adhered microorganisms to particle protecting them from disinfection, provide them source of nutrition and facilitate their movement within the distribution (USEPA 2006).

The mean Free Residual chlorine (FRC), mean Combined Residual chlorine and Total Residual Chlorine was found $0.24 \mathrm{mg} / \mathrm{l}, 0.06 \mathrm{gm} / \mathrm{l}$ and $0.3 \mathrm{gm} / \mathrm{L}$ respectively. Comparatively we found low FRC at far point than at near point, whereas combined residual chlorine was found highest in far point. In agreement to this study, Hu et al. (2005) also found the decrease in mean FRC from water plant outlets $(1.49 \mathrm{mg} / \mathrm{l})$ to the unit pipeline $(0.18 \mathrm{mg} / \mathrm{l})$ in Singapore. The decay of free residual chlorine occurs due to different factors such as temperature, $\mathrm{pH}$ as well as its reaction with different contaminants such as organic and inorganic material and with microorganism present in distribution system (USEPA 2006).

In the present study, mean HPC of water was found $\log _{10} 3.15$ which ranged from ND to $\log _{10} 5.70$. In drinking water samples 95.6\% (109/114) were found to have HPC of $>0 \mathrm{CFU} / \mathrm{ml} \mathrm{or} \mathrm{cm}^{2}$. In the study, conducted by Shrestha (2008), among 170 samples of piped water, 85.9\% samples revealed the presence of heterotrophic bacteria. Similarly high HPC in water was found in previous studies conducted in Korea (Lee \& Kim 2003) and Singapore (Hu et al. 2005). In this study, among the four distribution stations, HPC was found highest in water sample collected at Minbhawan and least was found in that of Balaju. However mean difference was found statistically insignificant. HPC of water not only increases the risk of potential pathogenic bacteria but it also degrades the aesthetic quality of drinking water (Momba \& Kaleni 2002). In context of distance, mean HPC of water was found highest in the far point samples and the mean difference was found statistically significant ( $\mathrm{p}=0.012$ ). According to Lee and Kim (2003), at the end of the distribution system high probability of microbiological problems occurs due to low chlorine concentration, increased retention time, decrease flow velocity and accumulation of detached bacteria from upstream in the distribution system.

In the present study, $61.4 \%$ (70/114) of the water samples were found to have coliform count above the recommended level of WHO guideline. Total coliform bacteria were more commonly present at far point than at near point in all distribution stations and the mean difference was found statistically significant ( $\mathrm{p}=0.004$ ). Among the 70 samples that contain Total coliform bacteria, $15.7 \%$ (11/70) were found to be contaminated with thermotolerant type coliform bacteria. In agreement to this study previous studies also indicate high coliform contamination rate in water samples of Kathmandu valley. Prasai et al. (2002) and Shrestha (2008) found all tested tap water samples contaminated with total Coliform. However Bajracharya et al. (2007) and Aryal (2009) reported $73.7 \%$ and $86.2 \%$ samples respectively contaminated with total coliform. Though slightly higher to present study, the recovery rate of thermotolerant Coliform was found low that is $19.6 \%$ (Aryal 2009) to 23.3\% (Shrestha 2008). Chaidez et al. (2008), detected $46 \%$ Total coliform and $26 \%$ faecal coliform in drinking water conducted in Mexico. The reason for such a 
high percentage of total coliform in drinking water may be due to the depletion of the residual chlorine through the pipeline and the water may gets contaminated due to leakage, rusty pipelines or sewage contamination. Besides, lack of adequate treatment facility in all water distribution point, intermittent supply and leakages causes a negative pressure which often draws contaminated material from the surface. The problem is worsened by the old distribution networks and biofilm on pipeline can act as the reservoir of the coliform and thermotolerant Coliform bacteria (USEPA 2006). According to USEPA (2006), most of the thermotolerant Coliforms isolated comprises of $E$. coli. It have stated that in one study, $96.96 \%$ of thermotolerant Coliforms are E. coli, followed by Enterobacter cloacae (2.32\%), K. pneumoniae (0.66\%) and Citrobacter freundii (0.33\%).

Table 1. Association of total coliform and distance from distribution stations

\begin{tabular}{l|l|l|l|l|l}
\hline \multicolumn{5}{c}{ Coliform count according to WHO guideline } & \multirow{2}{*}{ p-value } \\
\cline { 2 - 5 } Distant & Above WHO guideline & Within WHO guideline & \\
\cline { 2 - 5 } & Number & Percent & Number & Percent & 0.002 \\
Far point & 43 & $75.44 \%$ & 14 & $24.6 \%$ & \\
Near point & 27 & $47.4 \%$ & 30 & $52.6 \%$ & \\
Total & $\mathbf{7 0}$ & $\mathbf{6 1 . 4 \%}$ & $\mathbf{4 4}$ & $\mathbf{3 8 . 6 \%}$ & \\
\hline
\end{tabular}

Among 114 water samples, 10 different genera of Gram negative enteric bacterial isolates were found from 89 (78.1\%) water samples. Most prevalent bacteria in water samples collected were found to be $E$. coli followed by Pseudomonas spp., Citrobacter spp., Klebsiella spp., Shigella spp., Proteus spp., Enterobacter spp., NonTyphi Salmonella spp., Providencia spp. and Edwardsiella spp. similar results were also obtained in previous studies (Shrestha 2008, Bhatta \& Kapadnis 2008). The recovery rate of $E$. coli is high in contaminated drinking water samples (Hoefel et al. 2005).

Table 2. Antibiotics sensitivity pattern of water isolates

\section{Antibiotics sensitivity pattern of isolates from water}

\begin{tabular}{l|c|c}
\hline Isolates (N) & AR & MAR \\
\hline Citrobacter spp. (5) & 2 & 1 \\
E. coli (10) & 6 & 4 \\
Edwardsiella spp. (1) & 2 & - \\
Enterobacter spp. (2) & 2 & - \\
Klebsiella spp. (4) & - & 4 \\
Proteus spp. (2) & - & 1 \\
Providencia spp. (1) & 1 & - \\
Pseudomonas spp. (6) & 2 & 5 \\
Non-Typhi Salmonella spp. (2) & 3 & - \\
Shigella spp. (4) & $\mathbf{1 9 ~ ( 5 0 \% )}$ & $\mathbf{1 5 ( 3 9 . 5 \% )}$ \\
\hline Total (38)
\end{tabular}

Antibiotics susceptibility test was conducted in 38 water isolates against 12 different antibiotics. All isolates showed sensitivity to Gentamicin and Ofloxacin followed by Ceftazidime and Ceftriazone (97.14\%), Ciprofoxacin and Chloramphnicol (94.29\%), Tobramycin and Nalidixic acid (85.71\%), Cotrimoxazole (82.86\%), and least sensitivity was shown against Ampicillin (11.43\%). Similarly, Shrestha (2008) also found high resistance among drinking water isolates against Ampicillin (93.9\%). Losch et al. (2008) in Argentina and Tambedkar et al. (2008) in India found that Ampicillin was least effective antibiotic for water isolates. Our study indicated higher percentage of AR and MAR bacteria in drinking water samples. The present study highlights the need of improvement in drinking water quality of Kathmandu valley.

\section{Acknowledgements}

The authors are highly thankful Nepal Academy of Science and Technology (NAST) for providing laboratory and associated facilities The National Public Health Laboratory (NPHL) provided us the reference bacterial cultures. The authors are also thankful to all the participants of this study for their immense support and providing required information and water samples.

\section{References}

APHA. 1998. Standard methods for the examination of water and wastewater. $20^{\text {th }}$ edition. American Public Health Association, Washington, DC.

Aryal, S.N. 2009. Isolation and characterization of Escherichia Coli from drinking water of urban Kathmandu. M. Sc. Dissertation. Central Department of Microbiology, Tribhuvan University, Kirtipur, Kathmandu, Nepal. 
Prabin Shakya et al./Evaluation of Physicochemical.

Bajracharya, A.M., K.D. Yami, T. Prasai, S.R. Basnyat and B. Lekhak. 2007. Assessment of drinking water quality of Kathmandu metropolitan areas. Nepal Journal of Science and Technology 8:113-118.

Bauer, A.W.K, J.C. Sherris and T. Truck. 1966. Antibiotic susceptibility testing by a standardized single disk method. Am. J. Clin .Pathol. 45: 493-496.

Bhatta, D.R. and B. Kapadnis. 2008. Microbiological quality of city water supply in Nepal. In: $4^{\text {th }} A S M$ conference on biofilm 2007. American Society of Microbiology, Washington DC, 137 pp.

Chaidez, C., M. Soto, C. Martinez and B. Keswick. 2008. Drinking water microbiological survey of the northwestern state of Sinaloa, Mexico. J. Water and Health 6(1):125-129.

Collee, J.G., A.G. Frasher., B.P. Marmion and A. Simmons. 1996. Mackie and McCartney Practical Medical Microbiology. $14^{\text {th }}$ edition, Churchill Living Stone.

DoHS. 2004/2005. Annual report. Ministry of Health and Population, Department of Health services, Kathmandu, Nepal.

Flournoy, R., D. Monroe, N. Chestnut and V. Kumar. 1999. Health effects from vinyl chloride monomer leaching from Pre-1977 PVC pipe. AWWA Annual Conference Proceedings, USA.

Gaur, A., P.W. Ramteke and S.P. Pathak. 1992. Transferable antibiotic resistance among thermotolerant Coliform from rural drinking water in India. Epidemiol. Infect 109: 113-120.

Hoefel, D., P.T. Monis, W.L. Grooby, S. Andrews and C.P. Saint. 2005. Culture-independent techniques for rapid detection of bacteria associated with loss of chloramine residual in a drinking water system. Appl. and Environ. Microbiol. 71:6479-6488.

Holt, J.G, Krieg, N.R. P. H. A. Sneath, J. T. Staley, T. Stanley W. 1994. Bergey's manual of determinative bacteriology. Ninth Edition, International edition.

Hu, J.Y., B. Yu, Y.Y. Feng, X.L. Tan, S.L. Ong, W.J. Ng and W.C. Hoe. 2005. Investigation into biofilms in a local drinking water distribution system. Biofilms 2:19-25

Lee, D.G. and S.J. Kim. 2003. Bacterial species in biofilm cultivated from the end of the Seoul water distribution system. J. Appl. Microbiol. 95:317-324.
Losch, S.L., J.M. Alonso and L.A. Merino. 2008. Occurrence of antimicrobial-resistant enterobacteriaceae in water from different sources in a subtropical region of Argentina. Rivista Ambi-Agua 3(2):28-36.

Momba, M.N. and P. Kaleni. 2002. Re-growth and survival of indicator microorganisms on the surfaces of household containers used for the storage of drinking water in rural communities of South Africa. Water Res. 36:3023-3028.

Payment, P. 1997. Epidemiology of endemic gastrointestinal and respiratory diseases-incidence, fraction attributable to tap water and cost to society. Water Sci. Technol.35:710.

Prasai, T., D.R. Joshi, B. Lekhak and M.P. Baral 2007. Microbiological analysis of drinking water of Kathmandu valley. Scientific World 5:112-114.

September, S.M., F.A. Els, S.N. Venter, and V.S. Brozel. 2007. Prevalence of bacterial pathogens in biofilms of drinking water distribution systems. $J$ Water Health 5: 219-227.

Shrestha, R. 2008. Assessment of drinking water quality of Kathmandu and study of antibiotics sensitivity pattern and oligodynamic action against bacterial isolates. M.Sc. dissertation. National College, Tribhuvan University, Kathmandu, Nepal.

Stewart, J., J.W. Santo-Domingo and T. J. Wade. 2007. Fecal pollution, public health and microbial source tracking. In: Microbial Source Tracking (Eds. J.W. SantoDomingo \& M.J. Sadowsky). ASM Press, Washington D.C. pp. 1-32.

Tambedkar, D.H., H.R. Dhore, A.D. Kotwal, A. P. Shirbhate and P.B. Solav. 2008. Prevalence and antibiotic sensitivity profile of human enteric pathogens from different water sources in salinity affected villages of Vidarbha (India). Res. J. Agric. Biol. Sci. 4(6):712-716.

USEPA. 2006. Distribution system indicators of drinking water quality. USEPA, Washington, DC.

World Health Organization (WHO). 2004. Water, sanitation and hygiene links to health: facts and figures. World Health Organization, Geneva, Switzerland.

World Health Organization, Regional office for South-East Asia (WHO-SEARO). 2010. Drinking water quality in the South-East Asia Region. Mahatma Gandhi Marga, New Delhi, India. 
Nepal Journal of Science and Technology Vol. 13, No. 2 (2012) 179-184 